\title{
High-throughput phenotyping of two plant-size traits of Eucalyptus species using neural networks
}

\author{
Marcus Vinicius Vieira Borges ${ }^{1} \cdot$ Janielle de Oliveira Garcia $^{1} \cdot$ Tays Silva Batista $^{1}$. \\ Alexsandra Nogueira Martins Silva ${ }^{1}$ - Fabio Henrique Rojo Baio ${ }^{1} \cdot$ Carlos Antônio da Silva Junior $^{2}$. \\ Gileno Brito de Azevedo ${ }^{1}$ - Glauce Taís de Oliveira Sousa Azevedo ${ }^{1} \cdot$ Larissa Pereira Ribeiro Teodoro $^{1}$. \\ Paulo Eduardo Teodoro ${ }^{1}$
}

Received: 9 March 2021 / Accepted: 23 April 2021 / Published online: 3 June 2021

(C) The Author(s) 2021

\begin{abstract}
In forest modeling to estimate the volume of wood, artificial intelligence has been shown to be quite efficient, especially using artificial neural networks (ANNs). Here we tested whether diameter at breast height (DBH) and the total plant height (Ht) of eucalyptus can be predicted at the stand level using spectral bands measured by an unmanned aerial vehicle (UAV) multispectral sensor and vegetation indices. To do so, using the data obtained by the UAV as input variables, we tested different configurations (number of hidden layers and number of neurons in each layer) of ANNs for predicting DBH and $\mathrm{Ht}$ at stand level for different Eucalyptus species. The experimental design was randomized blocks with four replicates, with 20 trees in each experimental plot. The treatments comprised five Eucalyptus species (E. camaldulensis, E. uroplylla, E. saligna, E. grandis, and E. urograndis) and Corymbria citriodora. DBH and $\mathrm{Ht}$ for each plot at the stand level were measured seven times in separate overflights by the UAV, so that the multispectral sensor could obtain spectral bands to calculate vegetation indices (VIs). ANNs were then constructed using spectral bands and VIs as input layers, in addition to the categorical
\end{abstract}

Project funding: The work was supported in part by the Coordenação de Aperfeiçoamento de Pessoal de Nível Superior Brazil (CAPES), Finance Code 001.

The online version is available at http://www.springerlink.com

Corresponding editor: Tao Xu

Paulo Eduardo Teodoro

eduteodoro@hotmail.com

1 Federal University of Mato Grosso Do Sul (UFMS), Chapadão Do Sul, Mato Grosso Do Sul 79560000, Brazil

2 Department of Geography, State University of Mato Grosso (UNEMAT), Sinop, Mato Grosso 78555000, Brazil variable (species), to predict DBH and $\mathrm{Ht}$ at the stand level simultaneously. This report represents one of the first applications of high-throughput phenotyping for plant size traits in Eucalyptus species. In general, ANNs containing three hidden layers gave better statistical performance (higher estimated $r$, lower estimated root mean squared error-RMSE) due to their greater capacity for self-learning. Among these ANNs, the best contained eight neurons in the first layer, seven in the second, and five in the third $(8-7-5)$. The results reported here reveal the potential of using the generated models to perform accurate forest inventories based on spectral bands and VIs obtained with a UAV multispectral sensor and ANNs, reducing labor and time.

Keywords Computational intelligence $\cdot$ Diameter at breast height $\cdot$ Forest inventory $\cdot$ Remote sensing . Vegetation indices

\section{Introduction}

With the recent growth in the forestry sector in Brazil, the planted forest area in 2018 reached 7.83 million ha, representing $1.3 \%$ of the GDP and $6.9 \%$ of the industrial GDP (IBÁ 2019). Species of Eucalyptus are favored for wood production in commercial forests in Brazil as one of the main strategies to reduce the deforestation of native forests and supply wood for energy and timber (Ferraz et al. 2019).

One of the factors determining the success in obtaining high yielding forests is the choice of species since each species has specific characteristics and adaptation to edaphoclimatic conditions. According to Brisola and Demarco (2011), $E$. grandis grows well but has little resistance to drought, while E. urophylla produces wood with a slightly higher density but slower growth. Breeding programs have helped 
provide genotypes with high resistance to pests, good adaptability to various climatic conditions, and desirable characteristics for the timber industry, such as E. urograndis, a hybrid of E. grandis and E. urophylla (Fernández et al. 2018). E. saligna is known to have higher wood density than E. grandis (Batista et al. 2010). According to Azevedo et al. (2015), E. camaldulensis has high adaptability in less fertile soils and resistance to drought. Corymbia citriodora a gum tree endemic to Australia, stands out for the high mechanical resistance of its wood (Morais et al. 2010).

For assessing tree performance in forest inventories in delimited field plots, diameter to breast height (DBH) and total height $(\mathrm{Ht})$ of the trees are the most commonly selected dendrometric variables to measure directly. These variables are then used to generate estimates of production variables (volume, biomass), which are then extrapolated to the total plantation area. However, such inventories are expensive; plots that are representative of the entire population must be taken out of production, and the highly precise measurements that are required for decision-making require skilled labor and are complicated due to the complexity of forest formations (Shao et al. 2020).

For consecutive evaluations of quantitative and qualitative variables of interest in forest breeding, high-throughput phenotyping can be time-consuming and provide a low level of spatial and temporal information. Thus, to improve the efficiency of phenotyping, new tools with high precision and data quality must be adopted (Sankaran et al. 2019). For this purpose, remote sensing techniques make it possible to measure plant traits with high precision in a shorter field time (Jay et al. 2017). Thus, remote sensing can accurately and quickly provide $\mathrm{DBH}$ and $\mathrm{Ht}$ data for phenotyping and thus reduce the costs of forest inventories.

Currently, there are multispectral sensors aboard space platforms, and more recently, on aerial platforms such as unmanned aerial vehicles (UAVs) that can assist with phenotyping. Spectral bands are measured in the region from visible to near-infrared spectral bands of the electromagnetic spectrum, allowing a wide range of vegetation indices (VIs), which are mathematical ratios, to be calculated (Rezzouk et al. 2019). One of the main VIs used for high-throughput phenotyping is the normalized difference vegetation index (NDVI) (Hentz et al. 2018). Like all indices created to simplify what are otherwise complex amalgamations of data, the NDVI has great appeal in commercial agriculture and land-use studies because of its ability to quickly delineate vegetation and vegetative stress (Huang et al. 2020).

In forest modeling to estimate the volume of wood, artificial intelligence has been shown to be quite efficient, especially using artificial neural networks (ANNs). This technique has high generalization power and is better for generating nonlinear models unknown to the modeler, among other characteristics, in relation to the regression models (Vieira et al. 2018). Recently, ANNs have been used to estimate the volume of wood using inputs such as DBH, Ht, among others (Soares et al. 2012; Bhering et al. 2015; Miguel et al. 2016; Azevedo et al. 2020). However, to the best of our knowledge, there are no reports of the use of a UAV multispectral sensor to obtain variables as input in ANNs to predict DBH and Ht of Eucalyptus trees.

We hypothesized that the DBH and $\mathrm{Ht}$ at the stand level in Eucalyptus can be predicted using spectral bands and vegetation indices. Therefore, we tested different configurations (number of hidden layers and number of neurons in each layer) of ANNs for predicting DBH and $\mathrm{Ht}$ at stand level in different Eucalyptus species using input variables obtained by UAV-multispectral sensor.

\section{Materials and methods}

\section{Experimental site and setup}

The experiment was installed in January 2014 in the experimental area of the Federal University of Mato Grosso do Sul, Chapadão do Sul campus. The altitude is $820 \mathrm{~m}$ a.s.l. The soil is classified as medium-textured Red Oxisol. According to the Köppen classification, the climate is tropical humid (Aw) with a rainy season from October to April and a dry season between May and September. Average rainfall varies from 750 to $1800 \mathrm{~mm} \mathrm{a}^{-1}$, and average annual temperature varies from $20^{\circ} \mathrm{C}$ to $25^{\circ} \mathrm{C}$ (Peel et al. 2007).

All fertilization requirements were determined from a soil chemical analysis. The following results were obtained: $\mathrm{pH}\left(\mathrm{CaCl}_{2}\right)$ : 4.9; organic matter: $31.5 \mathrm{~g} \mathrm{dm}^{-3}$; phosphorus: $13.6 \mathrm{mg} \mathrm{dm}^{-3}$; hydrogen + aluminium $(\mathrm{H}+\mathrm{Al}): 5.4$; potassium: $0.29 \mathrm{cmol}_{\mathrm{c}} \mathrm{dm}^{-3}$; calcium: $2.8 \mathrm{cmol}_{\mathrm{c}} \mathrm{dm}^{-3}$; magnesium: $0.5 \mathrm{cmol}_{\mathrm{c}} \mathrm{dm}^{-3}$; cation exchange capacity (CEC): $9.0 \mathrm{cmol}_{\mathrm{c}} \mathrm{dm}^{-3}$; base saturation: $39.9 \%$. The proportions of clay, sand, and silt were $46 \%, 46 \%$, and $8 \%$, respectively. Crowning, weeding, ant control, and application of herbicides (glyphosate) were performed when necessary.

The experimental design was randomized blocks with four repetitions, with 20 plants in each experimental plot. The treatments were composed of five Eucalyptus species (E. camaldulensis, E. uroplylla, E. saligna, E. grandis and E. urograndis) and Corymbria citriodora.

\section{Evaluated variables}

The diameter at breast height (DBH) and total plant height (Ht) at stand level were obtained by measuring the same five trees in each experimental unit throughout the 1-year study. A tape measure was used to measure the circumference at breast height, which was later converted to DBH. The Ht (m) was obtained with the aid of a Haglof 
hypsometer. The variables were measured seven times for each tree (11/01/2018, 12/06/2018, 01/22/2019, 03/29/2019, $05 / 10 / 2019,10 / 30 / 2019$, and 11/28/2019). Figure 1 shows the climatic conditions in the experimental area during these assessments.

The characteristics related to high-throughput phenotyping were obtained on the same dates using the senseFly eBee (Cheseaux-sur-Lausanne, Switzerland) RTK fixed-wing unmanned aerial vehicle (UAV) with autonomous flight control (Fig. 2). We used a Parrot Sequoia sensor (Prilly, Switzerland), a multispectral camera for agriculture that uses a sunshine sensor and an additional RGB camera 16 MP for scouting. Radiometric calibration was performed for the entire scene, based on calibrated reflective surfaces. The Pix4D mapper (Prilly, Switzerland) software was used to correcting the parameters of solar irradiation, and the reflective target of the camera with reflectance calibration plate was individualized for each device. For the entire scene, information was obtained on the reflectance rates for each spectral band measured by the multispectral sensor. This procedure is performed in the field immediately using

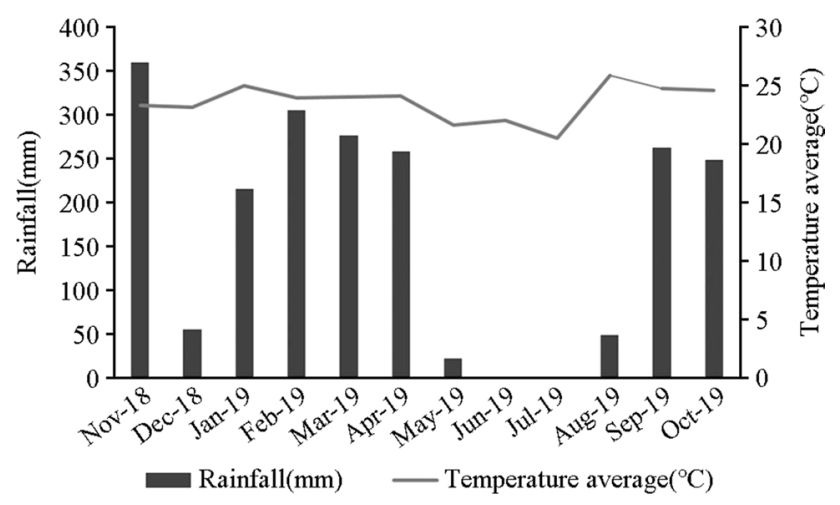

Fig. 1 Rainfall and temperature at the experimental site in Brazil during the experiment in 2018 and 2019
senseFly e-Motion software (Cheseaux-sur-Lausanne, Switzerland) before the flight. Because the flight has a maximum duration of $15 \mathrm{~min}$, there was no need to repeat the calibration after the flight in the field.

The multispectral sensor had a horizontal field of view (HFOV) of $61.9^{\circ}$, vertical field of view (VFOV) of $48.5^{\circ}$, and diagonal field of view (DFOV) of $73.7^{\circ}$. Multispectral reflectance images were obtained for green $(550 \mathrm{~nm} \pm 40 \mathrm{~nm})$, red $(660 \mathrm{~nm} \pm 40 \mathrm{~nm})$, red-edge $(735 \mathrm{~nm} \pm 10 \mathrm{~nm})$ and near-infrared (Nir, $790 \mathrm{~nm} \pm 40 \mathrm{~nm}$ ) spectral bands. The obtained values were then used to calculate the following VIs according to Table 1: normalized difference vegetation index (NDVI), soil-adjusted vegetation index (SAVI), green normalized difference vegetation index (GNDVI), normalized difference red-edge (NDRE), simplified canopy chlorophyll content index (SCCCI), enhanced vegetation index (EVI) and modified soil-adjusted vegetation index (MSAVI). These VIs are the main ones that can be calculated with the

Table 1 Equations and sources of the vegetation indexes (VI) used for high performance phenotyping

\begin{tabular}{lll}
\hline VI & Equation & References \\
\hline NDVI & $\frac{\text { NIR-Red }}{\text { NIR+Red }}$ & Rouse et al. (1974) \\
SAVI & $(1+0.5) \frac{\text { NIR-Red }}{\text { NIR+Red }+0.5}$ & Huete (1988) \\
GNVDI & $\frac{\text { NIR-Green }}{\text { NIR+Green }}$ & Gitelson et al. (1996) \\
NDRE & $\frac{\text { IIR-Red edge }}{\text { NIR+Red edge }}$ & Gitelson and Merzlyak (1994) \\
SCCCI & $\frac{\text { NDRE }}{\text { NDVI }}$ & Raper and Varco (2015) \\
EVI & $\frac{\text { NIR-Red }}{(\text { NIR+6Red-7.5Green)+1 }}$ & Huete et al. (2002) \\
MSAVI & $\frac{2 \text { NIR+1- } \sqrt{(2 N I R+1)^{2}}-(8 N I R-R e d)}{2}$ & Qi et al. (1994)
\end{tabular}

NIR Near infrared, NDVI Normalized difference vegetation index, $S A V I$ Soil-adjusted vegetation index, GNDVI green normalized difference vegetation index, NDRE Normalized difference red-edge, SCCCI Simplified canopy chlorophyll content index, EVI enhanced vegetation index, MSAVI modified soil-adjusted vegetation index
Fig. 2 The eBee RTK fixed-wing unmanned aerial vehicle (UAV) coupled with the senseFly Sequoia multispectral sensor

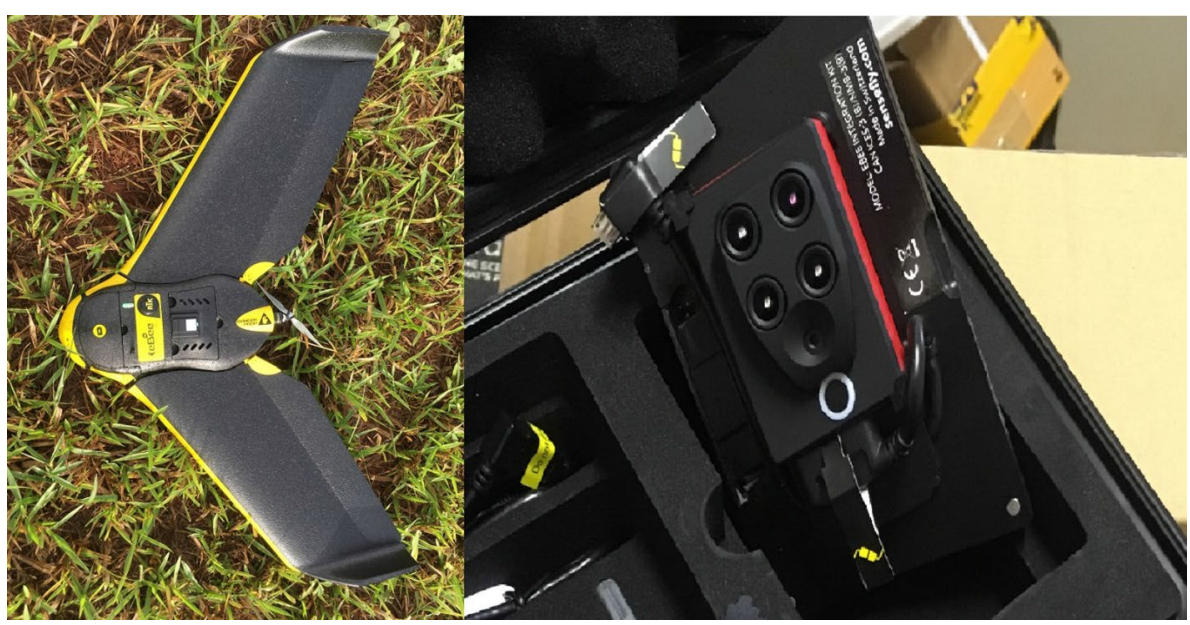


spectral bands obtained. In addition, they have already been used for high yield phenotyping in agricultural species, due to their correlation with plant biomass (Osco et al. 2020; Ramos et al. 2020).

The overflights were performed with $80 \%$ lateral and $85 \%$ longitudinal overlap of the images, and the same area was imaged twice using perpendicular flight lines. The increase in the overlap between the images was necessary to obtain a greater number of scenes containing the same control points, allowing greater accuracy in the mosaic of the images by the Pix4Dmapper software. This need is based on plant height, because the stem oscillates as a function of the wind, and regardless of the speed, interferes in the mosaicking process. The overflight was performed at $100 \mathrm{~m}$ altitude, allowing a spatial image resolution of $0.10 \mathrm{~m}$. The overflights were carried out near the zenith due to the minimization of the shadows of the trees at 11 a.m., given that the multispectral sensor is a passive type (i.e., dependent on solar luminosity).

\section{Statistical analyses}

To verify the existence of plant size differences among the Eucalyptus species, a joint analysis of variance (ANOVA) was performed according to the statistical model in Eq. 1.

$Y_{i j k}=\mu+B_{k}+E_{i}+M_{j}+E M_{i j}+e_{i j k}$

where $Y_{i j k}$ is the observation in the $k$-th block evaluated in the $i$-th species and $j$-th measurement, $\mu$ is the overall mean, $B_{k}$ is the block effect considered as fixed, $E_{i}$ is the species effect considered as fixed, $M_{j}$ is the measurement effect considered as random, $E M_{i j}$ is the random effect of the interaction between species $i$ and measurement $j$, and $e_{i j k}$ is the random error associated with $Y_{i j k}$ observation.
Pearson's correlation coefficients $(r)$ were estimated to verify the association between grown traits with spectral bands and VIs according to Eq. 2:

$r_{X Y}=\frac{\operatorname{COV}_{X Y}}{\sqrt{\hat{\sigma}_{x}^{2}} \times \hat{\sigma}_{y}^{2}}$

where $\operatorname{COV}_{X Y}$ is the covariance between the traits $X$ and $Y$, $\hat{\sigma}_{x}^{2}$ is the phenotypic variance of trait $X$, and $\hat{\sigma}_{y}^{2}$ is the phenotypic variance of trait $Y$. We used the correlation network to graphically express the results. In this procedure, green lines link variables that are positively correlated and red lines to join negatively correlated variables. The line thickness is proportional to the magnitude of the correlation.

Subsequently, for developing and training the ANNs, the Intelligent Problem Solver tool of stattista STATISTICA 7.0 (Hamburg, Germany) was used. This tool performs data mining, i.e., normalizes data in the $0-1$ range, tests different network architectures (multilayer merceptron [MLP] or radial basis function [RBF]), and selects the best performing networks. In MLP networks, the input layer was composed of spectral bands and vegetation indices, besides the categorical variable species; the output layer was composed of two layers corresponding to DBH and $\mathrm{Ht}$ at stand level. For intermediate layer(s), we used the activation function $f(x)=$ logistic (Eq. 3) applied to each neuron, which uses the scalar product of the input vector $(x)$ and the weight vector $(w)$ associated with this node. For these networks, topologies containing two and three layers with one to 15 neurons each and a high degree of connectivity between the neurons were tested, which is defined by synaptic weights (Fig. 3).
Fig. 3 General topology of the evaluated artificial neural networks. NIR: near infrared; NDVI: normalized difference vegetation index; SAVI: soil-adjusted vegetation index; GNDVI: green normalized difference vegetation index; NDRE: normalized difference red-edge; SCCCI: simplified canopy chlorophyll content index; EVI: enhanced vegetation index; MSAVI: modified soil-adjusted vegetation index; DBH: diameter at breast height; Ht: plant height

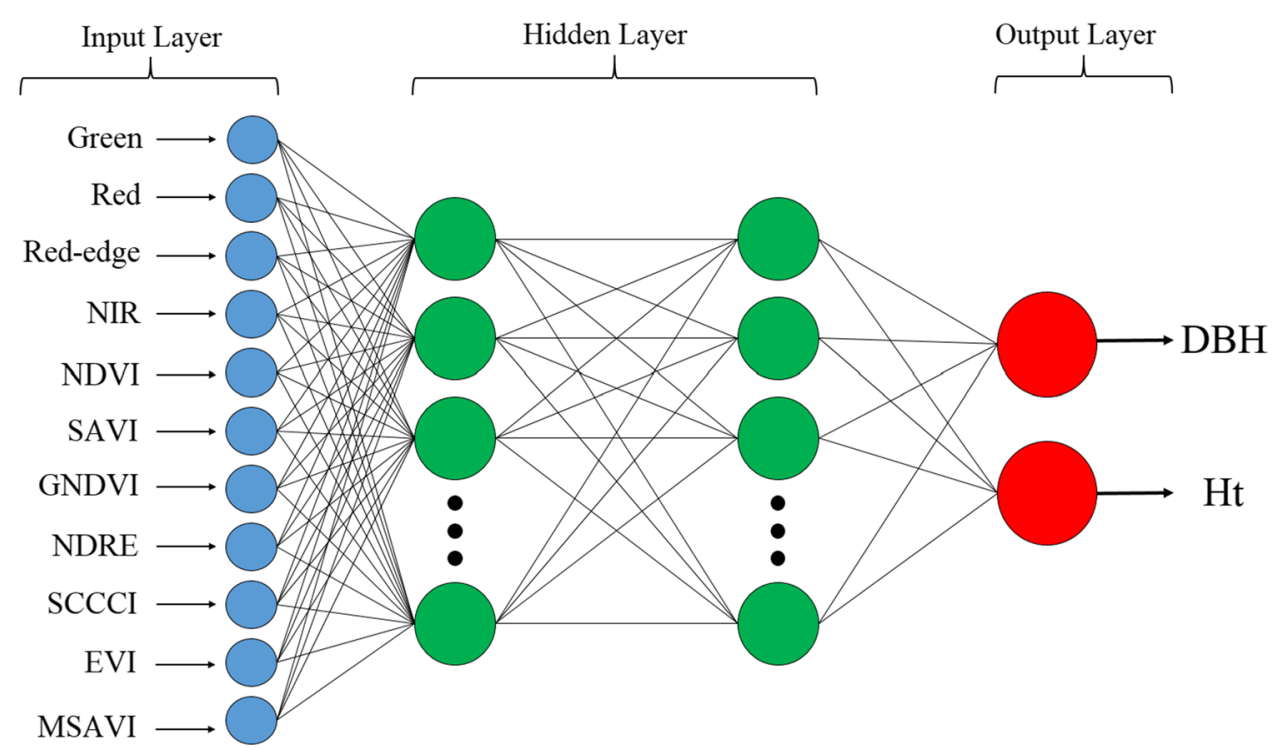


$f(x)=\frac{1}{1+e^{x}}$

where $x$ is a binary value that represents the activation of the neuron (1) versus non-activation (0).

The training used was feedforward by the supervised method. Therefore, 3600 ANN topologies were tested, composed of the following combinations: MLP with two hidden layers $(15 \times 15$ possibilities $)$ and MLP with three hidden layers $(15 \times 15 \times 15$ possibilities $)$. Only the 10 ANNs with the highest linear correlation between observed versus predicted volumes in the training step were saved. For training, $80 \%$ of the data was used, and the remaining $20 \%$ were used to validate the 10 best neural networks.

For selecting the best ANNs in each step (training and validation), Pearson's correlation coefficient $\left(r_{X Y} ;\right.$ Eq. 4) and root mean square error (RMSE; Eq. 5) were used.

$r_{X Y}=\frac{\operatorname{COV}_{X Y}}{\sqrt{\hat{\sigma}_{x}^{2} \times \hat{\sigma}_{y}^{2}}}$

where $\mathrm{COV}_{X Y}$ is the covariance between the observed $(X)$ and predicted $(Y)$ values; $\hat{\sigma}_{x}^{2}$ is the variance of observed values; $\hat{\sigma}_{y}^{2}$ is the variance of predicted values.

$\operatorname{RMSE}(\%)=\frac{100}{\bar{Y}} \sqrt{\frac{\sum_{i=1}^{n}\left(Y_{i}-\hat{Y}_{i}\right)}{n}}$

where $\hat{Y}_{i}$ is the mean of the observed values; $n$ is the total number of observations.

\section{Results and discussion}

The joint ANOVA identified that a statistically significant difference between the species for all the traits evaluated (Table 2). The effect of measurements was significant $(p \leq 0.05)$ for most traits, except for red and red-edge spectral bands and NDVI, SCCCI and EVI. There was no species $\times$ measurements interaction for $\mathrm{DBH}$ or $\mathrm{Ht}$ at the stand level, showing that the species E. grandis was the tallest at each date. It is important to note that the estimates of the coefficient of variation were less than $20 \%$ for all traits evaluated, which is considered high precision for forest experiments (Garcia 1989).

Among the species studied, E. grandis was largest for $\mathrm{DBH}$ and $\mathrm{Ht}$ at the stand level at all measurements, and $E$. camaldulensis was the smallest for both variables (Fig. 4). E. grandis, besides having the largest size, also had a smaller standard error, i.e., the plants had a distribution closer to the mean. E. urograndis was not as large as E. grandis, but larger than the other species. However, E. urograndis grows
Table $2 P$-values for $F$-test in the joint analysis of variance for the variables diameter at breast height $(\mathrm{DBH})$, total height $(\mathrm{Ht})$, spectral bands (green, red, red-edge, and NIR) and vegetation indices (NDVI, SAVI, GNDVI, NDRE, SCCCI, EVI, and MSAVI) evaluated for five Eucalyptus species

\begin{tabular}{lllllc}
\hline Variable & Blocks & Species (E) & $\begin{array}{l}\text { Measure- } \\
\text { ment }(\mathrm{M})\end{array}$ & $\mathrm{E} \times \mathrm{M}$ & $\begin{array}{c}\text { Coefficient of } \\
\text { variation }(\%)\end{array}$ \\
\hline DBH & 0.01 & 0.00 & 0.00 & 0.99 & 11.54 \\
$\mathrm{Ht}$ & 0.41 & 0.00 & 0.00 & 0.85 & 8.86 \\
Green & 0.42 & 0.00 & 0.04 & 0.00 & 13.04 \\
Red & 0.41 & 0.00 & 0.10 & 0.00 & 10.38 \\
Red-edge & 0.19 & 0.00 & 0.10 & 0.01 & 19.87 \\
NIR & 0.26 & 0.00 & 0.01 & 0.00 & 18.46 \\
NDVI & 0.00 & 0.00 & 0.08 & 0.00 & 2.94 \\
SAVI & 0.01 & 0.00 & 0.02 & 0.00 & 7.50 \\
GNVDI & 0.27 & 0.00 & 0.00 & 0.00 & 2.41 \\
NDRE & 0.04 & 0.00 & 0.00 & 0.08 & 5.88 \\
SCCCI & 0.02 & 0.00 & 0.06 & 0.91 & 8.15 \\
EVI & 0.33 & 0.00 & 0.16 & 0.12 & 8.56 \\
MSAVI & 0.00 & 0.00 & 0.00 & 0.02 & 7.78 \\
\hline
\end{tabular}

NDVI Normalized difference vegetation index, SAVI soil-adjusted vegetation index, GNDVI green normalized difference vegetation index, NDRE normalized difference red-edge, SCCCI simplified canopy chlorophyll content index, EVI enhanced vegetation index, MSAVI modified soil-adjusted vegetation index

well in the study region, so the higher means for $E$. grandis proves that is better adapted to the conditions.

Macedo et al. (2006) studied the development of two E. camaldulensis clones and two E. urophylla clones in an integration system and observed that the E. camaldulensis clones had higher means. These findings differ from those obtained here, where E. urophylla obtained the fourth-highest means and E. camaldulensis the lowest means. In work by Embrapa (2019) on different Eucalyptus species, means for trait sizes for E. urograndis and E. grandis were very close, similar to the findings obtained here.

The study site has adequate pluviometric rates, resulting in a satisfactory plant size of $E$. grandis, which has low drought resistance (Embrapa 2010). E. camaldulensis, however, is susceptible to the insect pest psilidus (Camargo 2011), which is present in the experimental region, and the trees were smaller as a consequence of psilidus attack. Considering the great variability obtained between species in different measurements, this data set is robust for training and validating ANN models.

The correlation network in Fig. 5 shows a high and positive correlation between the plant size traits (DBH and $\mathrm{Ht}$ ). The red-edge and NIR spectral bands had a positive linear correlation with the plant size traits, so these spectral bands stood out for estimating DBH and $\mathrm{Ht}$. The vegetation indices NDVI, GNVDI, EVI, NDRE, MSAVI, SAVI, and SCCCI were poorly correlation with the plant 

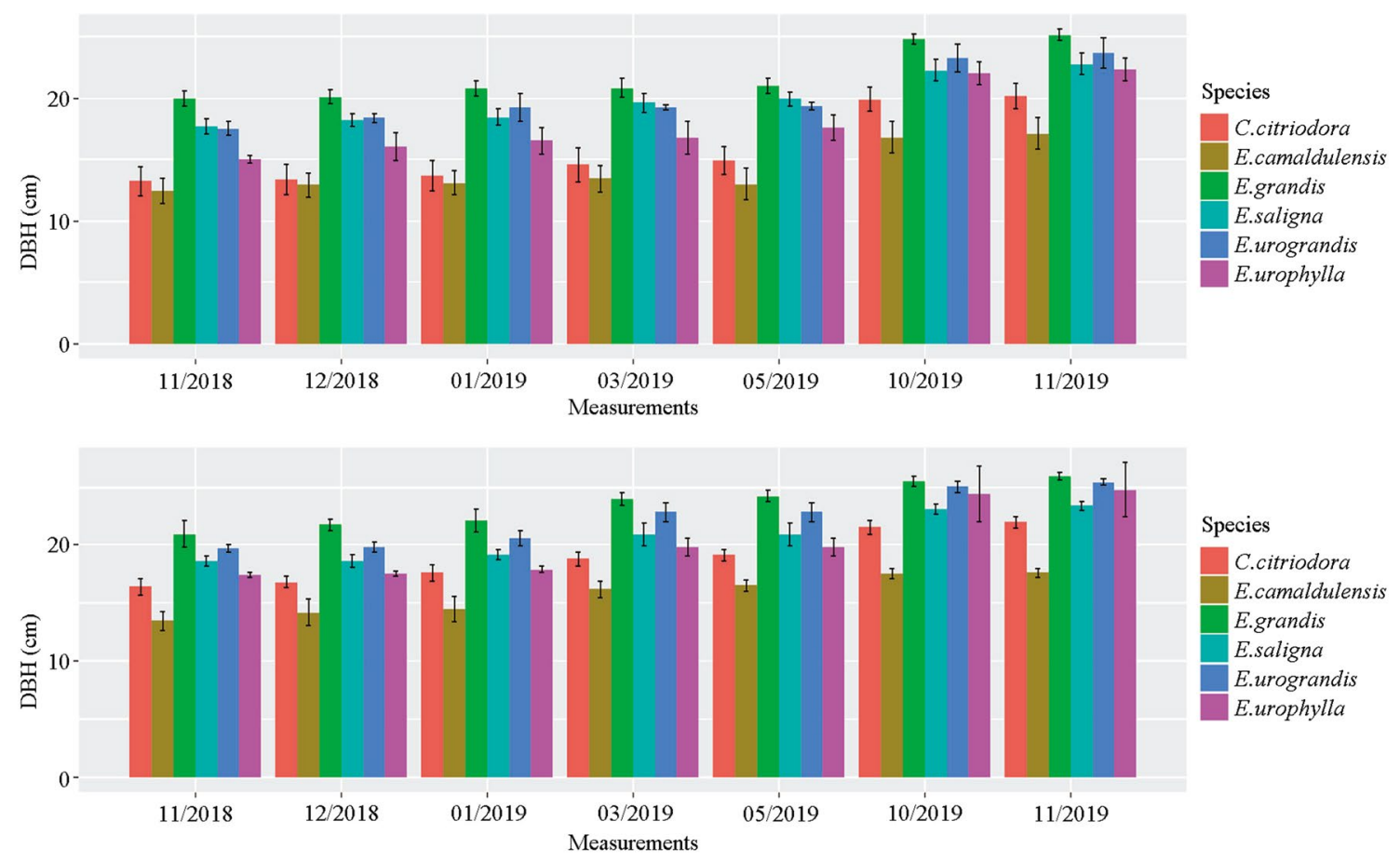

Fig. 4 Means for diameter at breast height $(\mathrm{DBH}, \mathrm{cm})$ and total height $(\mathrm{Ht}, \mathrm{m})$ at the stand level for six Eucalyptus species measured between November 2018 and November 2019

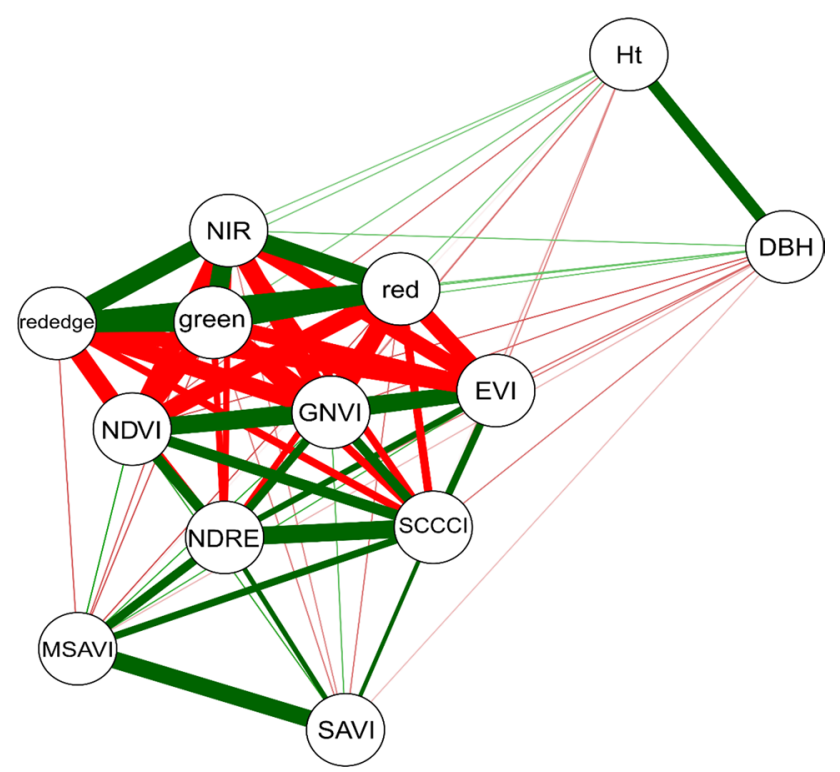

Fig. 5 Pearson's correlation network for diameter at breast height $(\mathrm{DBH})$, total height $(\mathrm{Ht})$, spectral bands (green, red, red-edge, and NIR), and vegetation indices normalized difference vegetation index (NDVI), soil-adjusted vegetation index (SAVI), green normalized difference vegetation index (GNDVI), normalized difference rededge (NDRE), simplified canopy chlorophyll content index (SCCCI), enhanced vegetation index (EVI) and modified soil-adjusted vegetation index (MSAVI) evaluated in Eucalyptus species. Green lines link variables that are positively correlated; red lines join negatively correlated variables. The thicker the line, the stronger the correlation size traits, which can be explained by the relationship between these variables with the canopy of the Eucalyptus species. The higher the leaf area index (LAI), the higher will be the VI estimates. However, for forest species, the presence of abundant leaves indicates the presence of trees, hence a lower commercial wood volume.

Marsden et al. (2010) also found low correlations between the NDVI and the mean annual increment (MAI), where this correlation was progressively increasing throughout the plant size and establishment of the forest. Bikindou et al. (2012) compared multiple regressions related to soil properties, and the NIR index was correlated with dominant height for productive capacity classification. According to these authors, the NIR provided a better correlation and a low mean square error for better predicting index variations in the studied area. Maire et al. (2011) used MODIS reflectance and NIR to estimate LAI and found significant correlations; however, NIR overestimates the variable at young ages.

Forest tree species produce more stems and leaves at lower $\mathrm{Ht}$ and DBH (Almeida et al. 2015). LAI is also larger at younger ages when the development in $\mathrm{Ht}$ and $\mathrm{DBH}$ is lower. With increasing age, DBH and Ht increase, and leaf area decreases. The VIs follow the leaf mass, i.e., the greater the leaf production, the higher the vegetation index, thus explaining the negative and low magnitude correlation between vegetation indices and plant size traits at the stand 
Table 3 Statistical performance $(r, \mathrm{RMSE})$ and topologies (number of hidden layers and number of neurons per hidden layer) of the 10 best artificial neural networks selected for estimating DBH and $\mathrm{Ht}$ of five Eucalyptus species at the stand level

\begin{tabular}{|c|c|c|c|c|c|c|c|c|}
\hline \multirow[t]{3}{*}{ Topology } & \multicolumn{4}{|c|}{ Training } & \multicolumn{4}{|c|}{ Validation } \\
\hline & \multicolumn{2}{|l|}{$\mathrm{DBH}$} & \multicolumn{2}{|l|}{$\mathrm{Ht}$} & \multicolumn{2}{|l|}{ DBH } & \multicolumn{2}{|l|}{$\mathrm{Ht}$} \\
\hline & $r$ & $\operatorname{RMSE}(\%)$ & $r$ & RMSE (\%) & $r$ & RMSE (\%) & $r$ & RMSE (\%) \\
\hline $1-4$ & 0.60 & 13.78 & 0.62 & 10.56 & 0.78 & 14.67 & 0.81 & 10.55 \\
\hline $7-4$ & 0.61 & 13.74 & 0.63 & 10.13 & 0.78 & 14.55 & 0.81 & 10.84 \\
\hline $7-1$ & 0.76 & 11.22 & 0.75 & 8.81 & 0.87 & 11.25 & 0.85 & 9.22 \\
\hline $7-2$ & 0.79 & 10.58 & 0.76 & 8.51 & 0.88 & 10.57 & 0.85 & 8.63 \\
\hline $7-3$ & 0.80 & 10.27 & 0.77 & 8.19 & 0.90 & 9.81 & 0.87 & 8.64 \\
\hline $7-2-4$ & 0.82 & 9.77 & 0.80 & 7.87 & 0.94 & 8.45 & 0.90 & 7.39 \\
\hline $7-4-4$ & 0.83 & 9.37 & 0.81 & 7.70 & 0.94 & 8.42 & 0.92 & 6.48 \\
\hline $7-6-6$ & 0.83 & 9.32 & 0.81 & 7.62 & 0.94 & 8.31 & 0.92 & 6.42 \\
\hline $7-6-9$ & 0.84 & 9.17 & 0.81 & 7.54 & 0.94 & 8.55 & 0.93 & 6.11 \\
\hline $8-7-5$ & 0.85 & 8.81 & 0.83 & 7.04 & 0.93 & 8.81 & 0.94 & 5.54 \\
\hline
\end{tabular}

$D B H$ Diameter at breast height, $H t$ Total height, $r$ Correlation coefficient, RMSE Root mean square error level since high indices are correlated with smaller plant size.

The low association between spectral bands and VIs with the plant size traits demonstrates that nonlinear techniques must be used to predict these variables. In this sense, ANNs stand out because they have the ability to learn in a nonlinear way, and through the input data, they are able to generate their architecture and free parameters that can predict the output data with high accuracy in the training process (Costa et al. 2019). According to Nieto et al. (2012), ANNs have been widely used to solve regression problems with good performance in forest studies and are suitable for more complex modeling situations.

The statistical performance of the 10 best ANNs is presented in Table 3. The results show a good ability to simultaneously predict plant size traits (DBH and $\mathrm{Ht}$ ) at the stand level using the variables obtained with high-throughput phenotyping (spectral bands and VI's). Overall, persons correlation coefficient $(r)$ values between the estimated and predicted data increased at the validation step compared to the training step, but RMSE was reduced at the validation step. In general, artificial neural networks containing three hidden layers showed better statistical performance (higher estimate of $r$ and lower estimate of RMSE) due to their greater capacity for self-learning. These results show that there was no overfitting for the 10 best ANNs. Vendruscolo et al. (2015) found similar results when using ANNs to estimate $\mathrm{Ht}$ as a function of $\mathrm{DBH}$, with $r$ close to 0.90 and the RMSE less than $10 \%$.

The high-throughput phenotyping associated with ANNs made it possible to accurately predict (high correlation, low error) the plant size at the stand level of Eucalyptus species. Thus, the ANNs trained in this study make it possible to predict DBH and $\mathrm{Ht}$ of eucalyptus trees simultaneously at stand level, that is, when feeding the ANN with spectral bands and vegetation indices. Thus, the costs of forest inventories are reduced, since only VIs and spectral bands are needed to predict the variables measured in the inventory process.

\section{Conclusions}

In general, artificial neural networks (ANNs) containing three hidden layers showed better statistical performance (higher estimate of $r$, lower estimate of RMSE) due to their greater capacity for self-learning. Among these ANNs, the best contains eight neurons in the first layer, seven in the second, and five in the third (8-7-5). Thus, the models associated with ANNs can provide accurate forest inventories using spectral bands and VIs obtained with a multispectral sensor on a UAV, reducing time and labor.

Acknowledgements The authors would like to thank the Federal University of Mato Grosso do Sul (UFMS) and National Council for Scientific and Technological Development (CNPq) - Grant number 303767/2020-0.

Open Access This article is licensed under a Creative Commons Attribution 4.0 International License, which permits use, sharing, adaptation, distribution and reproduction in any medium or format, as long as you give appropriate credit to the original author(s) and the source, provide a link to the Creative Commons licence, and indicate if changes were made. The images or other third party material in this article are included in the article's Creative Commons licence, unless indicated otherwise in a credit line to the material. If material is not included in the article's Creative Commons licence and your intended use is not permitted by statutory regulation or exceeds the permitted use, you will need to obtain permission directly from the copyright holder. To view a copy of this licence, visit http://creativecommons.org/licenses/by/4.0/. 


\section{References}

Almeida AQ, Ribeiro A, Delgado FC, Rody YP, Oliveira AS, Leite FP (2015) Eucalyptus leaf area index estimated by vegetation indices using Landsat-5 TM images. Flor Amb. https://doi.org/10.1590/ 2179-8087.103414

Azevedo LPA, Costa RB, Martinez DT, Tsukamoto Filho AA, Brondani GE, Baretta MC, Ajala WV (2015) Genetic selection in Eucalyptus camaldulensis progenies in savanna area of Mato Grosso State Brazil. Cien Flor. https://doi.org/10.1590/0103$8478 \mathrm{cr} 20131557$

Azevedo GB, Tomiazzi HV, Azevedo GTDOS, Teodoro LPR, Teodoro PE, de Souza MTP, Guerra SPS (2020) Multi-volume modeling of Eucalyptus trees using regression and artificial neural networks. Plos one. https://doi.org/10.1371/journal.pone.0238703

Batista DC, Klitzke RJ, Santos CVT (2010) Basic density and retractibility of wood clones of three Eucalyptus species. Cien Flor 20(4):665-674. https://doi.org/10.5902/198050982425

Bhering LL, Cruz CD, Peixoto LDA, Rosado AM, Laviola BG, Nascimento M (2015) Application of neural networks to predict volume in eucalyptus. Crop Breed Appl Biotechnol. https://doi.org/10. 1590/1984-70332015v15n3a23

Bikindou FDA, Gomat HY, Deleporte P, Bouillet JP, Moukini R, Mbedi Y, Ngouka E, Brunet D, Sita S, Diazenza JP, Vouidibio J, Mareschal L, Ranger J, Saint-André L (2012) Are NIR spectra useful for predicting site indices in sandy soils under Eucalyptus stands in Republic of Congo? For Ecol Manag 266(15):126-137. https:// doi.org/10.1016/j.foreco.2011.11.012

Brisola SH, Demarco D (2011) Stem anatomical analysis of Eucalyptus grandis, E. urophylla and E. grandis $\times$ urophylla: wood development and its industrial importance. Scient Flor 39(91):317-330

Camargo JMM (2011) Seleção de clones, absorção e translocação de silício, e seu efeito sobre a população do psilídeo-de-concha Glycaspis brimblecombei (Moore) (Hemiptera: Psyllidae) em plantas de Eucalyptus camaldulensis Dehn. Universidade Federal do Paraná, Thesis

Costa LR, Tonoli GHD, Milagres FR, Hein PRG (2019) Artificial neural network and partial least square regressions for rapid estimation of cellulose pulp dryness based on near infrared spectroscopic data. Carbohy Polym. https://doi.org/10.1016/j.carbpol. 2019.115186

Embrapa (2010) Zoneamento climático de Eucalyptus grandis para a região Sul do Brasil. https://ainfo.cnptia.embrapa.br/digital/bitst ream/item/39479/1/Doc209.pdf [acessed on 26.05.2020].

Embrapa (2019) Avaliação do desempenho silvicultural e econômico de cinco materiais genéticos de Eucalyptus em sistema silvipastoril, no bioma Pampa do Rio Grande do Sul. https://www.infot eca.cnptia.embrapa.br/infoteca/bitstream/doc/1110967/1/CT434 1645final.pdf [acessed on 21.04.2020].

Fernández M, Alaejos J, Andivia E, Vázquez-Piqué J, Ruiz F, López F, Tapias R (2018) Eucalyptus $\times$ urograndis biomass production for energy purposes exposed to a Mediterranean climate under different irrigation and fertilisation regimes. Biom Bioen 111:22-30. https://doi.org/10.1016/j.biombioe.2018.01.020

Ferraz SRB, Rodrigues CB, Garcia LG, Alvares CA, Lima WP (2019) Effects of Eucalyptus plantations on streamflow in Brazil: moving beyond the water use debate. For Ecol Manag. https://doi.org/10. 1016/j.foreco.2019.117571

Garcia CH (1989) Tabelas para classificação do coeficiente de variação. IPEF, Piracicaba, p 10

Gitelson AA, Merzlyak MN (1994) Quantitative estimation of chlorophyll-a using reflectance spectra: experiments with autumn chestnut and maple leaves. J Photochem Photobiol B Biol 22:247-252
Gitelson AA, Kaufman YJ, Merzlyak MN (1996) Use of a green channel in remote sensing of global vegetation from EOS-MODIS. Remote Sens Environ 58:289-298

Hentz AMK, Silva CA, Corte APD, Netto SP, Strager MP, Klauberg C (2018) Estimating forest uniformity in Eucalyptus spp and Pinus taeda L stands using field measurements and structure from motion point clouds generated from unmanned aerial vehicle UAV data collection. For Syst. https://doi.org/10.5424/fs/20182 $72-11713$

Huang S, Tang L, Hupy JP, Wang Y, Shao GF (2020) A commentary review on the use of normalized difference vegetation index (NDVI) in the era of popular remote sensing. J Forestry Res 32:16. https://doi.org/10.1007/s11676-020-01155-1

Huete AR (1988) A soil-adjusted vegetation index (SAVI). Rem Sens Environ 25:295-309

Huete A, Didan K, Miura T, Rodriguez EP, Gao X, Ferreira LG (2002) Overview of the radiometric and biophysical performance of the M.O.D.I.S. vegetation indices. Rem Sens Environ 83:195-213

IBÁ (2019) Relatório IBÁ 2019. https://iba.org/eng/datafiles/publi cacoes/relatorios/iba-relatorioanual2019.pdf [acessed on 21.04.2020].

Jay S, Maupas F, Bendoula R, Gorretta N (2017) Retrieving LAI, chlorophyll and nitrogen contents in sugar beet crops from multi-angular optical remote sensing: comparison of vegetation indices and PROSAIL inversion for field phenotyping. Field Crops Res 210:33-46. https://doi.org/10.1016/j.fcr.2017.05.005

Macedo RLG, Bezerra RG, Venturin N, Vale RS, Oliveira TK (2006) Silvicultural performance of eucalyptus clones and agronomic characteristic of corn planted in agroforestry systems. Ver Arv. https://doi.org/10.1590/S0100-67622006000500003

Maire G, Marsden C, Verhoef W, Ponzoni FJ, Lo Visto D, Begue A, Stape JL, Nouvellon Y (2011) Leaf area index estimation with MODIS reflectance time series and model inversion during full rotations of Eucalyptus plantations. Rem Sens Env 115(2):586599. https://doi.org/10.1016/j.rse.2010.10.004

Marsden C, Maire G, Stape JL, Seen D, Roupsard O, Cabral O, Epron D, Lima AMN, Nouvellon Y (2010) Relating MODIS vegetation index time-series with structure, light absorption and stem production of fast-growing Eucalyptus plantations. For Ecol Manag 259(9):1741-1753. https://doi.org/10.1016/j. foreco.2009.07.039

Miguel EP, Mota FICM, Teo SJ, Nascimento RGM, Leal FIA, Pereira RSE, Rezende AVE (2016) Artificial intelligence tools in predicting the volume of trees within a forest stand. Afr J Agric Res 11(21):1914-1923

Morais E, Zanatto ACS, Freitas MLM, Moraes MLT, Sebbenn AM (2010) Genetic variation, genotype $\times$ soil interaction and genetic gains in a Corymbia citriodora Hook progeny test in Luiz Antonio, Sao Paulo. Brazil For Sci 38(85):11-18

Nieto PJG, Torres JM, Fernández MA, Galán CO (2012) Support vector machines and neural networks used to evaluate paper manufactured using Eucalyptus globulus. Appl Mathem Mod 36(12):6137-6145. https://doi.org/10.1016/j.apm.2012.02.016

Osco LP, Junior JM, Ramos APM, Furuya DEG, Santana DC, Teodoro LPR, Teodoro PE (2020) Leaf nitrogen concentration and plant height prediction for maize using UAV-based multispectral imagery and machine learning techniques. Remote Sens 12(19):3237. https://doi.org/10.3390/rs12193237

Peel MC, McMahon FBL, TA (2007) Updated world map of the Köppen-Geiger climate classification. Hydrol Earth Syst Sci 11:1633-1644

Qi JG, Chehbouni AR, Huete AR, Kerr YH, Sorooshian S (1994) A modified soil adjusted vegetation index. Remote Sens Environ 48:119-126

Ramos APM, Osco LP, Furuya DEG, Gonçalves WN, Santana DC, Teodoro LPR, Pistori H (2020) A random forest ranking approach 
to predict yield in maize with uav-based vegetation spectral indices. Comp Elect Agric. https://doi.org/10.1016/j.compag.2020. 105791

Raper TB, Varco JJ (2015) Canopy-scale wavelength and vegetative index sensitivities to cotton plant size parameters and nitrogen status. Precis Agric 16:62-76

Rezzouk FZ, Gracia-Romero A, Kefauver SC, Gutiérrez NA, Aranjuelo I, Serret MD, Araus JL (2019) Remote sensing techniques and stable isotopes as phenotyping tools to assess wheat yield performance: Effects of growing temperature and vernalization. Plant Scien. https://doi.org/10.1016/j.plantsci.2019.110281

Rouse JWJ, Haas RH, Schell JA, Deering DW (1974) Monitoring vegetation systems in the Great Plains with ERTS. https://repository. exst.jaxa.jp/dspace/handle/a-is/570457. [acessed on 27.01.2020].

Sankaran S, Quirós JJ, Miklas PN (2019) Unmanned aerial system and satellite-based high resolution imagery for high-throughput phenotyping in dry bean. Comp Elect Agric. https://doi.org/10. 1016/j.compag.2019.104965

Shao J, Zhang WM, Mellado N, Wang N, Jin SG, Cai SS, Luo L, Lejemble T, Yan GJ (2020) SLAM-aided forest plot mapping combining terrestrial and mobile laser scanning. ISPRS J Photog
Rem Sens 163:214-230. https://doi.org/10.1016/j.isprsjprs.2020. 03.008

Soares FAAMN, Flôres EL, Cabacinha CD, Carrijo GA, Veiga ACP (2012) Recursive diameter prediction for calculating merchantable volume of Eucalyptus clones without previous knowledge of total tree height using artificial neural networks. Appl Soft Comp 12(8):2030-2039. https://doi.org/10.1016/j.asoc.2012.02.018

Vendruscolo DGS, Drescher R, Souza HS, Moura JPVM, Mamoré FM, Siqueira TADS (2015) Estimativa da altura de eucalipto por meio de regressão não linear e redes neurais artificiais. Rev Bras Biom 33(4):556-569

Vieira GC, Mendonça AR, Silva GF, Zanetti SS, Silva MM, Santos AR (2018) Prognoses of diameter and height of trees of eucalyptus using artificial intelligence. Scien Total Env 619-620:1473-1481. https://doi.org/10.1016/j.scitotenv.2017.11.138

Publisher's Note Springer Nature remains neutral with regard to jurisdictional claims in published maps and institutional affiliations. 